\title{
Effectiveness of Solar-powered Fence in Reducing Human - Wild Elephant Conflict (HEC) in Northeast Jhapa District, Nepal
}

\begin{abstract}
Bijaya Neupane ${ }^{1}$, Binod Khatiwoda ${ }^{2}$ and Subash Budhathoki ${ }^{3}$
Abstract

Human Elephant Conflict (HEC) is a product of complex interaction between human and elephant that represents the detrimental impact for both. This study was aimed to assess the effectiveness of $17 \mathrm{~km}$ solar-powered electric fence installed in 2015 in north-eastern part of Jhapa district (Bahundangi VDC) against transboundary herds of wild elephants (150-200) that annually enters into Nepal from India and caused HEC. For this study, the detailed information on HEC incidents (human casualty and injury, crop and property damage) before and after the fence installation was collected. Affected wards within Bahundangi VDC were purposively selected for households survey $(N=100)$, consultations and group discussions $(N=5)$ and participatory field observations. We encountered poor maintenance and care of the electric fence and in some places covered by grasses and climbers questioning its sustainability. In-spite of it, the number of incidents of HEC sharply reduced by $96.13 \%$. Before the fence (in 2014), the estimated economic loss per household per year in the VDC was 103 USD (crop=95 $U S D$ and property $=8$ USD). Remarkably, there was reduction in economic loss of crop and property damage by $93 \%$ and $96 \%$ respectively. Besides, chi-square test of independence showed that there was significant difference in damages among the 4 affected wards of Bahundangi VDC with respect to paddy crop but not with maize crop, cowshed and other properties. After the fence installation, only few elephants accidently entered in some areas by breaking the solar fence and caused few incidents of crop and property damages. From the overall evaluation, solar fence was found effective in reducing HEC by protecting human lives, crops and properties.
\end{abstract}

Keywords: elephant, conflict, electric fence, crop damage, property damage

Neupane B., Khatiwoda B., Budhathoki S. (2018): Effectiveness of Solarpowered Fence in Reducing Human-Wild Elephant Conflict (HEC) in Northeast Jhapa District, Nepal. Forestry: Journal of Institute of Forestry, Nepal. No. 15: page 13 to 27.

\footnotetext{
${ }^{1}$ Tribhuvan University, Institute of Forestry, Pokhara Campus, Pokhara, Nepal, Author corresponding email address :bijneu@gmail.com or bneupane@iofpc.edu.np

${ }^{2}$ Tribhuvan University, Institute of Forestry, Pokhara Campus, Pokhara, Nepal

${ }^{3}$ Kathmandu Forestry College, Kathmandu, Nepal
} 


\section{Introduction}

Elephants (Endangered-International Union for Conservation of Nature 2008, Annex I-Convention on International Trade in Endangered species of Wild Fauna and Flora, Protected-Government of Nepal), the mega-fauna of all existent terrestrial animal, play an important role of umbrella species in the ecosystem they inhabit (Perera 2009). The number of resident wild Asian elephants in Nepal is estimated to be between 147-171 animals, distributed in four isolated sub populations: Eastern, Central, Western and Far-western regions (Pradhan et al. 2011; Yadav et al. 2015). The area inhabited by elephants is spread over 135 village development committee (VDCs) in 19 districts (17 in lowland Terai and 2 in the hills) of Nepal, covering about 10,982 sq.km of forest area (Department of National Parks and Wildlife Conservation 2008).

Wild elephants are long ranging species whose strict fidelity behavior follows a fix route of seasonal migration from Assam in India up to eastern Nepal, passing through the foothills and plains of Jalpaiguri and Darjeeling of West Bengal (Lenin, Sukumar 2008). The westernmost population of these elephants in Northern West Bengal, now separated from its counterparts in the western and eastern daurs, is generally residential but some inward and outward movement occur through contiguous and fragmented landscape within the district and also across western International boundary. KoshiTappu Wildlife Reserve (KTWR) has witnessed an increasing number of migratory elephants entering its area since 2008 that have now come to reside permanently in the Park (Ram 2014). Elephant Conservation Action Plan (2009) also confirms that migratory elephants in Eastern Region of Nepal have been increased.

Human wildlife conflict (HWC) is a complex interaction between humans and wildlife and represents the detrimental impact to both (Awasthi, Singh 2015). It has become a burning issue in biodiversity conservation of Nepal. In highly populated countries of Asia including Nepal, human elephant conflict (HEC) poses serious threat to elephant survival in and around protected areas and corridor forests. In the lowland Terai region of Nepal, there is rapid migration of people from hilly regions that resulted in habitat fragmentation and became one of the major causes of crop damages by wild elephants (Shrestha et al. 2007) and overall increase in conflicts (Neupane et al. 2014). The resultant effects are interaction of wild 
elephants with human in the form of human casualties and injuries, crop losses, property damages, social fear and retaliatory killings of elephants (Acharya et al. 2016). Also, the relative economic loss of households who suffered from crop raiding is high in developing countries like Nepal because the farmers are poor and mostly depend on subsistence farming nearby forest areas. Official records of the DFO, Jhapa showed that during 2010-2012 elephants killed or injured 21 people, damaged 210 houses and other property worth NRs. 8 millions. This conflict is increasing because the number of elephants entering into human settlements of Jhapa has been increasing at recent years (Ram 2014). Formerly these elephants were temporary migrants of India, spending 3-7 months in the eastern Nepal, before returning to India via Bahundangi VDC. During their migration these elephants are put at risk and subjected to danger. The movements of herd were largely restricted to the Bahundangi VDC and due to the spatial unequal distribution of wards of Bahundangi, all wards were not equally affected by the wild elephants. Ward 1, 2, 8 and 9 are damaged most by the elephants because of closeness to the Mechi River. Protected corridors linking forested areas are lacking between India and Nepal, so safety migration to and from Nepal is not insured. Elephant population is indeterminate outside the protected areas of Nepal and no conservation measures have enacted to ensure their protection.

With the aim to mitigate HEC, $17 \mathrm{~km}$ solar powered fence has been installed in the international boundary along the Mechi River to deter the elephant movement across the international border with the support of World Bank and NTNC in 2015 (Ministry of Forests and Soil Conservation 2015). Before the installment of solar powered fence, the large herds of wild elephants used to enter into Jhapa in search of food and water, crossing the Mechi River, more frequently observed during paddy harvesting time (June/July and Sept/Nov). According to official record of DFO and newspaper report, it has been found that HEC cases have been sharply reduced after the fence installment (District Forest Office Jhapa 2016; The Kathmandu Post 2016). So, this study was aimed to assess the present condition of solar powered fence, different incidents of HEC (human causalities and injuries, crop and property damage) before and after the solar powered electric fence installment and evaluate the effectiveness of the fence in terms of saving the human lives, major crops (paddy and maize) and property losses. Furthermore, the monetary value of crop and property damages before the fence establishment was calculated. 


\section{Materials and Methods}

\section{Site description}

The study was carried out in Bahundangi Village Development Committee (BVDC) $\left(26^{\circ} 44^{\prime} 24^{\prime \prime} \mathrm{N}\right.$ and $\left.88^{\circ} 9^{\prime} 36^{\prime \prime} \mathrm{E}\right)$ of Jhapa District, Eastern lowland Nepal (Mechinagar Municipality-14; Province number 1 at present) (Fig. 1) (Shrestha, Koirala 2015). It is a remote village located in the north-east corner of the district. It lies $10 \mathrm{~km}$ North from Mahendra Highway and occupies an area of $57.26 \mathrm{sq} . \mathrm{km}$ and is stretched North-South along the Mechi River that delineates the eastern boundary between Nepal and India (Karki 2014).

The study area varies widely from around $60 \mathrm{~m}$ elevations in the south and $500 \mathrm{~m}$ to the north and average temperature varies from $16.4^{\circ} \mathrm{C}$ in winter to $30^{\circ} \mathrm{C}$ in summer, which is close to the tropical type of climate. Precipitation is $80 \%$ during monsoon season. The maximum and minimum average annual precipitation is 3001-5500 $\mathrm{mm}$ and $801-1200 \mathrm{~mm}$ respectively. The tropical rain forest and tropical deciduous forest i.e. Shorea robusta dominant is present in the Jhapa district, particularly in the Jalthal forest.

Though BVDC front line VDC were most affected, Shantinagar, Budabare, Dhaijan, Sanischare, Khudunabari, Arjun Dhara VDCs and part of Mechi Municipality were also affected from trans boundary elephant movements before fence installation. After the fence installation these herds were restricted to BVDC only because only few adult elephants entered the settlements by breaking the fence in evening or night and after consuming the ripe crops available within the border VDC (i.e. BVDC), they returned to the Indian forests early next morning. All wards (Fig. 2) are not equally distributed in BVDC. Ward number 1, 2, 8 and 9 are located in front line and therefore there is more probability of damage and loss incurred from wild elephants. Almost half of the area (largely ward 1, 2, 8 and 9) of BVDC lies within $3 \mathrm{~km}$ of solar fence while remaining half area (ward 3, 4, 5) lies in 3-6 km. 


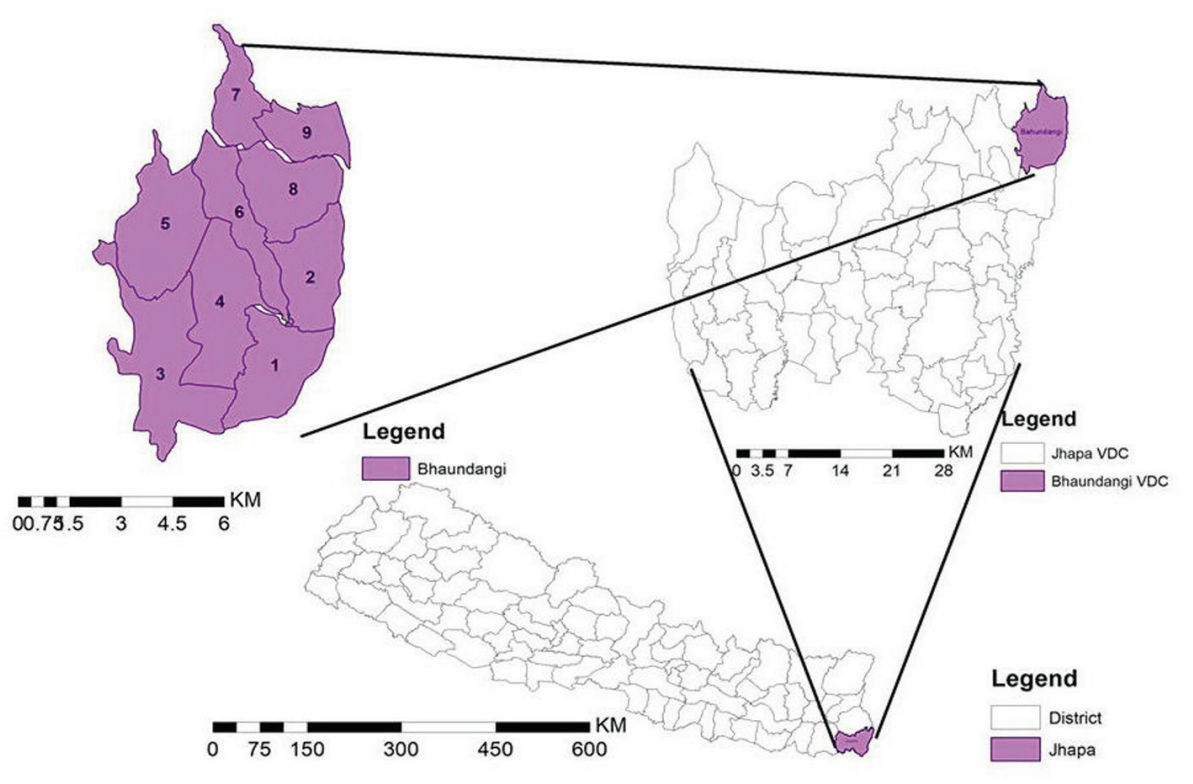

Fig. 1: Map showing the study area- Bahundangi VDC (BVDC)

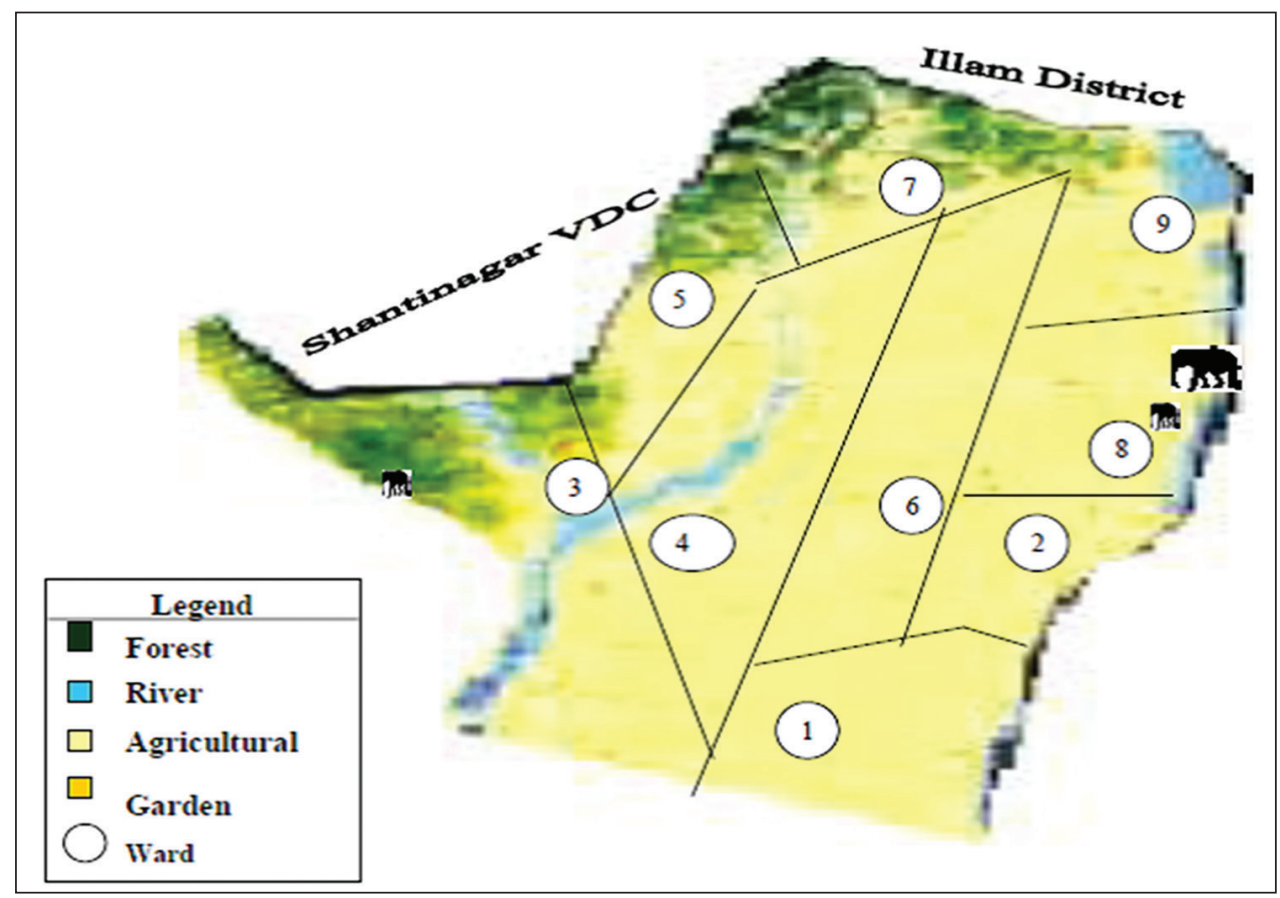

Fig. 2: Spatial distribution of wards in BVDC 


\section{Data Collection and Analysis}

\section{Preliminary field visit}

This visit was conducted to know which areas of BVDC were more affected in terms of human casualties, injuries, crop and property damage by trans boundary elephants before and after fence installation. During that survey, discussions were made with officials of DFO, Jhapa and local people.

\section{Major field works}

The field observations and surveys were conducted to identify the condition of the solar fence and monitor the crop and property damage areas. Based on the past official records of district forest office, Jhapa, the affected settlements of front line wards of BVDC were purposively selected and 100 households within those settlements were randomly selected for questionnaire survey. The questionnaires were prepared focusing on the human elephant conflict information from 2014 (before fence installment) and from 2017 (after fence installment). A questionnaire survey was conducted to analyze the average monetary value of crop and property loss per households per year before and after the fence establishment. In addition, key informant interviews were conducted with 30 local people who had been affected by HEC in the newly fenced areas to understand the in-depth situation of conflict and know the effectiveness of the solar fence and relief compensation mechanism. Besides, to triangulate information obtained from households survey and key-informants interviews, 4 representative group discussions (GDs) were made with local people (one from each affected wards: 1, 2, 8 and 9 of BVDC) regarding mitigation measures being applied and the effectiveness of solar powered fence and challenges in driving away elephants. For each GDs, participants were jointly from the local youth club, school teachers, political representative, representative from CFUG and civil society. Furthermore, participatory field observations for HEC incident points, particularly fence damage sites were surveyed. Signs of crop damages, elephant's dung and footprints were taken as the indicators for their presence in the settlement areas. All those affected sites were visited and crop and property damage information were recorded by asking with local people.

\section{Estimation of monetary value of crop and property loss}

Out of the total sampled households $(\mathrm{N}=100)$, the amount of crop losses due to elephants before fence installment was converted into monetary values based on the 
examination of the local market during the year 2014. The average monetary value was computed for 5 major crops practiced by the local people in the study area. Similar to the crop damage, the amount of property damage due to elephants before fence installment was converted into monetary values based on the examination of the local market during the year 2014. The average monetary value was computed for 4 major types of properties of local people in the study area.

\section{Secondary data collection}

Secondary data was collected from official records of DFO, Protected Area (PA), Department of National Parks and Wildlife Conservation (DNPWC), NTNC, published scientific literatures, articles, reports and books.

\section{Data analysis}

The data was analyzed using MS Excel, SPSS and Arc GIS. Most of the calculations and interpretations were performed using MS Excel while the prevalence of crop and property damages in 4 different wards of Bahundangi VDC were tested using Pearson's Chi-Square test of significance in SPSS. The significance of test was set at $P \leq 0.05$ (i.e. $5 \%$ level of significance). Among 4 categories of properties, the statistical tests were not performed for cowshed and other properties as they had minimum expected count values less than 5 , and so could not fulfill requirements for chi-square tests.

\section{Results}

\section{Condition of solar powered electric fence}

The fence was in poor condition due to lack of proper maintenance by the fence management committee as the cost of maintenance was reported expensive. There were no proper mechanisms to monitor and maintain the fence. Besides, some adult elephants were very clever and used dead dry logs to destroy the fence and sneak into the field as reported by the respondents. Bahundangi VDC was used as a major route to smuggle a wide range of goods during the night time as it lies in the foothill and away from the district headquarter, and there was no border security mechanism in the VDC to control such illegal activities. During night time, the smugglers used to disconnect the power fence in some places that allowed wild elephants to break the fence easily and enter into the agriculture fields. Besides, in some places, the fence was found covered by grasses and climbers (Fig. 3). 


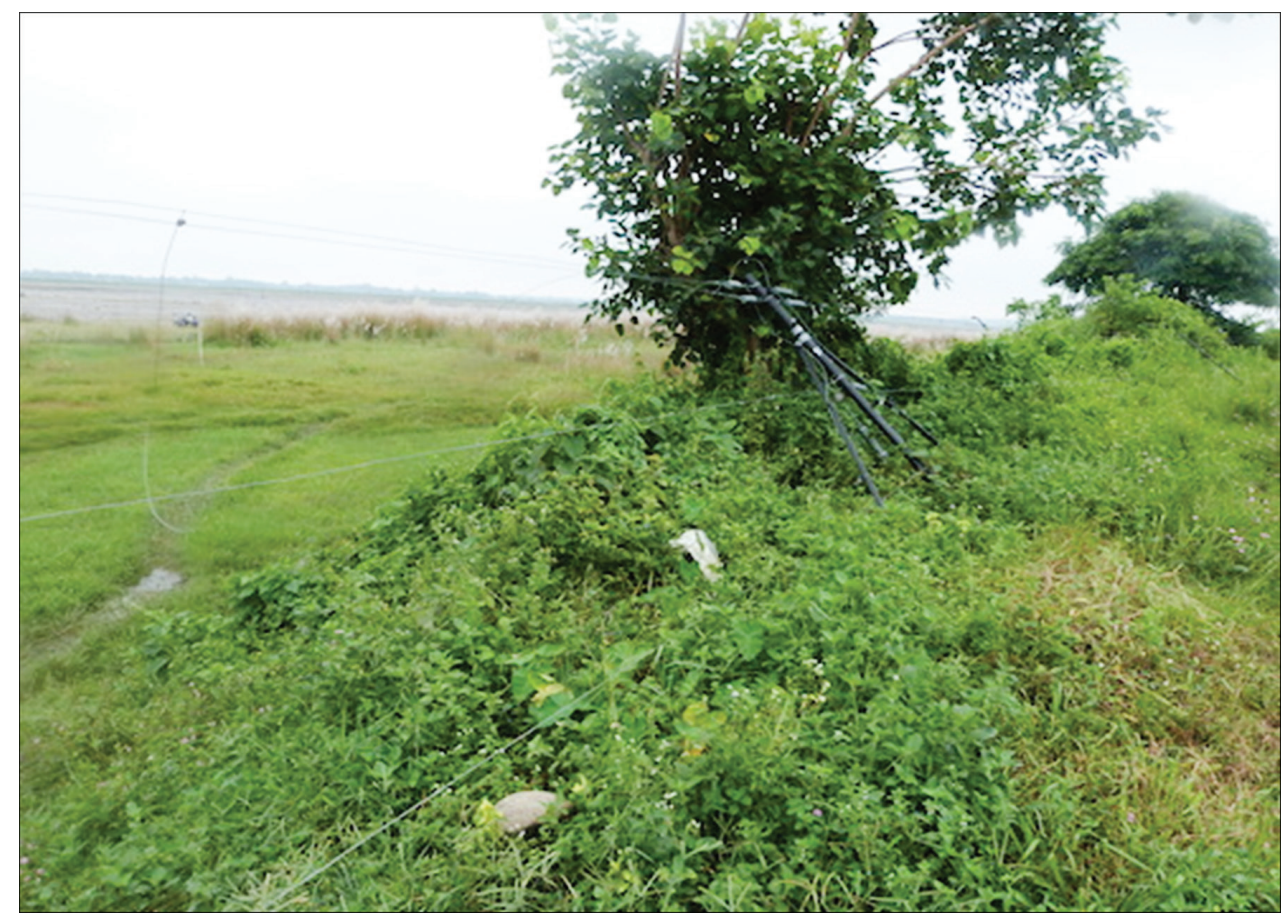

Fig. 3: Grasses and climbers covering solar-powered fence in Bahundangi VDC

\section{Effectiveness of the fence}

After the fence installation in 2015, it was found that the elephants had changed their behavior and adapted as opportunistic raider and they raided the crops along the fringes of Mechi River and immediately return to the Indian side. In June 2016, 116 elephants including 34 calves entered Jhapa but were not reported to move beyond the boundaries of Bahundangi (DFO Jhapa 2016). After the installment of solar fence, the huge herds of transboundary elephants were sharply decreased. Subsequently, the number of incidents of conflict (human casualty and injury, crop, property damage and retaliatory killings of elephants) was sharply decreased from 747 cases (before fence installment) to 30 (after fence installment) in 2016 with the percentage decreased of $96.13 \%$.

\section{Crop damage information}

Among different types of crops, the two major crops planted by the households were paddy (79\%) and maize (62\%) (Table 1). Among the surveyed households, $45 \%$ had experienced paddy crop damaged by wild elephants before fence installment that 
was sharply reduced to $3 \%$ of households after fence installment. Similarly, $29 \%$ of households had experienced maize crop damaged by wild elephants before fence installment that was sharply reduced to $2 \%$ of households after fence installment. Thus, the overall crop loss was noticeably reduced by around $93 \%$ after fence installment in the study area. From chi-square test of independence, it was found that there were significant differences on prevalence of paddy crop raided by wild elephants in 4 wards $(\chi 23,100=14.02 ; \mathrm{p} \leq 0.05)$ but not with maize crop $(\chi 2$ $3,100=7.14 ; \mathrm{p} \geq 0.05$ ).Additional information for other crop types are mentioned in Table 1. On average each household lost crop equivalent to approximately USD 95 due to transboundary elephants each year (Fig. 4) where the most affected crop was paddy.

\section{Property damage information}

Similarly, among different category of properties, the two major properties severely damaged by elephants were house/hut and stored grains (Fig. 5). Among the surveyed households, $32 \%$ had experienced house/hut damaged by wild elephants before fence installment that was sharply reduced to $2 \%$ of households after fence installment (Fig. 5). Similarly, 36\% of households had experienced stored grains damaged by wild elephants before fence installment that was drastically reduced to $1 \%$ of households after fence installment. Thus, the overall property loss was remarkably reduced by around $96 \%$ after fence installment in the study area. There were significant differences on prevalence of house/hut damages $(\chi 23,100$ $=16.54 ; \mathrm{p} \leq 0.05)$ by wild elephants among 4 wards. Similarly, the stored grains loss significantly differed among 4 wards $(\chi 23,100=10.77 ; \mathrm{p} \leq 0.05)$. Additional information for damage of other property types is mentioned in Fig. 5 and 6. Based on analysis, it was identified that on average each household lost property equivalent to approximately USD 8 annually (Fig. 6) where highest valued property damaged by elephants was house/hut. 


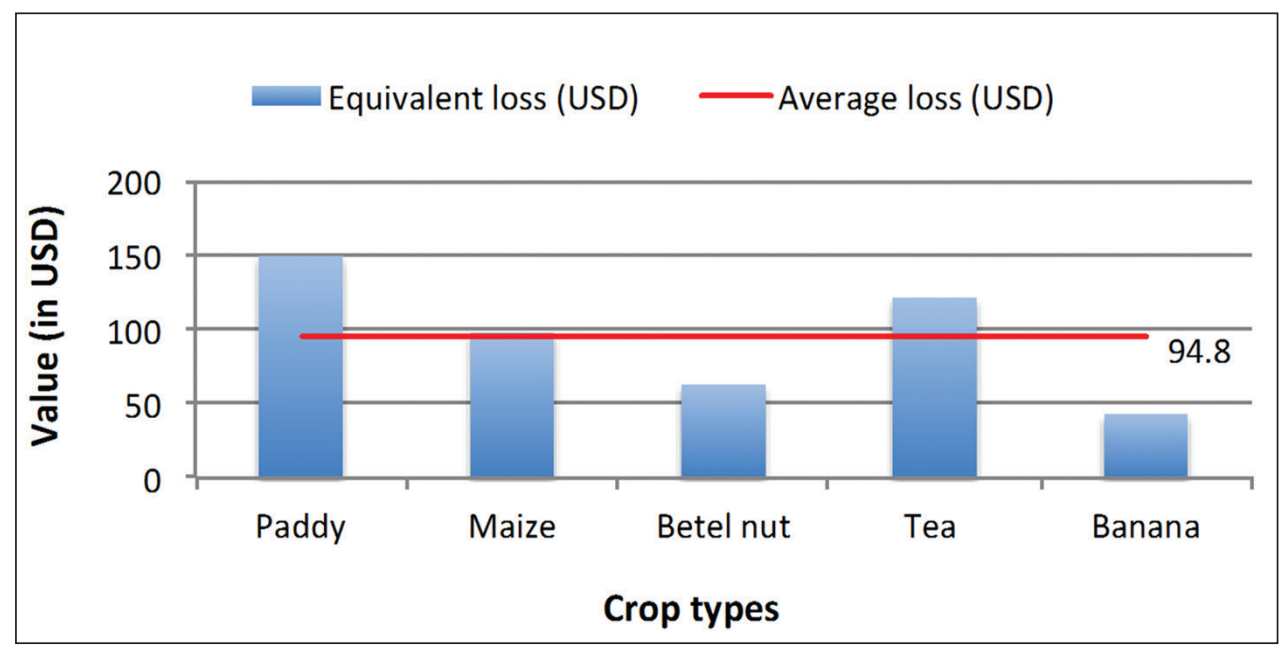

Fig. 4: Monetary equivalent value of crop damaged by wild elephants

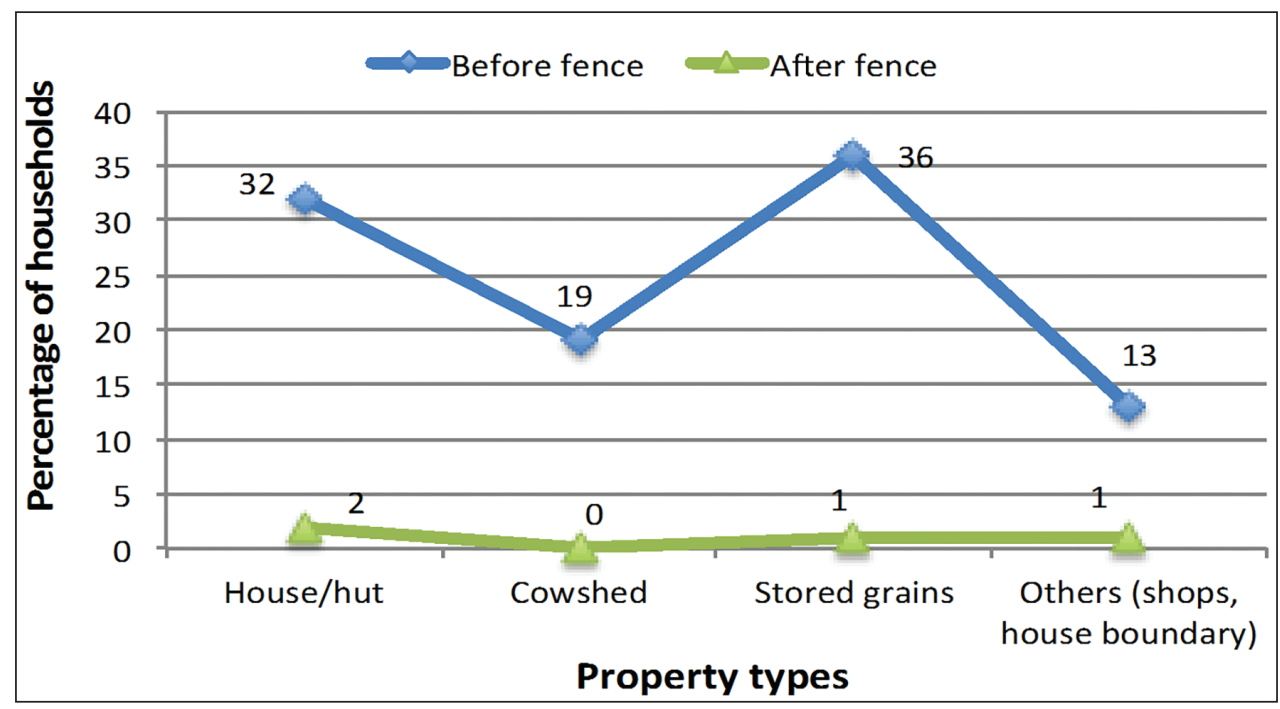

Fig. 5: Households' property damage information before and after solar fence 


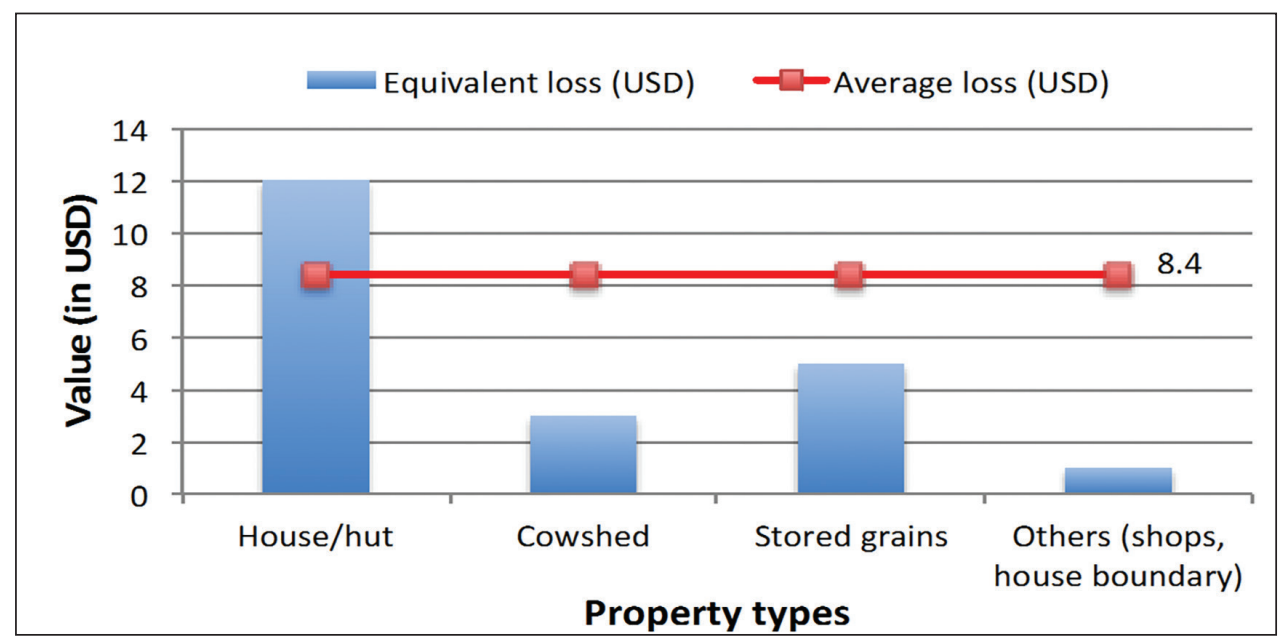

Fig. 6: Monetary equivalent value of property damaged by wild elephants

Table 1: Households' information on the major crops planted and raided before and after the solar powered fence installment.

\begin{tabular}{|l|c|c|c|c|c|c|c|c|}
\hline & \multicolumn{2}{|c|}{$\begin{array}{c}\text { Annual crop raided information before } \\
\text { fence installment (in 2014) }\end{array}$} & \multicolumn{3}{|c|}{$\begin{array}{c}\text { Annual crop raided information after } \\
\text { fence installment (in 2017) }\end{array}$} \\
\hline Crops & $\begin{array}{c}\text { Frequency } \\
\text { of HHs } \\
\text { (planted) }\end{array}$ & $\begin{array}{c}\text { Percent } \\
\text { of HHs } \\
\text { (planted) }\end{array}$ & $\begin{array}{c}\text { Frequency } \\
\text { of HHs } \\
\text { (crop } \\
\text { raided) }\end{array}$ & $\begin{array}{c}\text { Percent } \\
\text { of HHs } \\
\text { (crop } \\
\text { raided) }\end{array}$ & $\begin{array}{c}\text { Frequency } \\
\text { of HHs } \\
\text { (planted) }\end{array}$ & $\begin{array}{c}\text { Percent } \\
\text { of HHs } \\
\text { (planted) }\end{array}$ & $\begin{array}{c}\text { Frequency } \\
\text { of HHs } \\
\text { (crop } \\
\text { raided) }\end{array}$ & $\begin{array}{c}\text { Percent } \\
\text { of HHs } \\
\text { (crop } \\
\text { raided) }\end{array}$ \\
\hline Paddy & 79 & 79 & 45 & 45 & 79 & 79 & 3 & 3 \\
\hline Maize & 62 & 62 & 29 & 29 & 62 & 62 & 2 & 2 \\
\hline Betel nut & 33 & 33 & 13 & 13 & 33 & 33 & 1 & 1 \\
\hline Tea & 7 & 7 & 3 & 3 & 7 & 7 & 0 & 0 \\
\hline Banana & 5 & 5 & 3 & 3 & 5 & 5 & 0 & 0 \\
\hline
\end{tabular}

(Note: The 5 major crops are listed above based on the information that at least 5 households had planted the crops in the study area).

\section{Discussion}

To our knowledge, no any studies have been conducted so far to measure the effectiveness of solar powered fence in mitigating HEC in Jhapa district of Nepal. Based on our field observations and discussions with local people, we found that the ward numbers 2, 8 and 9 of Bahundangi VDC were the entry points where some 
transboundary elephants broke the fence and entered into maize and rice cultivated area, thereby damaging the crops and then returned to Indian forests again. Though till present the solar fence was found to be effective in reducing HEC and promoting livelihoods of local people, but the sustainability of the fence is challenging. From consultations and discussions, it was found that the monthly salary paid to the 12 field staffs staff for inspecting the fence was very low (i.e. USD 35 /person/month). Also, the staffs were not equipped and trained properly to repair the fences quickly and efficiently. Mostly, outside technicians were hired for repairing the broken fences. Another major challenge was that the fences were covered by the grasses and climbers in some places that restrict the flow of electric current in the wire. So, additional guarding is essential for the effectiveness of the fence through the mobilization of the local youth clubs in the BVDC of our study area.

However, this study showed that though the solar powered electric fence did not completely eliminated incidents of HEC but it had played a significant role in reducing several cases or incidents of HEC in Bahundangi VDC of Jhapa district Nepal. The settlements near to the fence had high incidence of elephant's attack than those far from the fence. Study conducted by Ram (2014) also concluded that BVDC wards that were close to Mechi bank were more vulnerable to HEC. Similar to our study, Davies et al. (2011) have investigated that among different mitigation measures, chili and electric fences were the most effective measures for reducing HEC including crop raiding. A study conducted by Kioko et al. (2008) in Kenya have reported that the success of electric fences depend upon the location of fences in relation to landscape factors, regular maintenance and proximity of fences to areas of high elephant concentration. They have also mentioned that the presence of electric current made no differences to the level of fence breaking by the elephants. In contrast to our study, a study conducted in Sri Lanka has mentioned that electric fences did not completely eliminate the problem of HEC (Gunaratne, Premarathne 2005). Instead they emphasized on strong community support for fence's planning, construction and maintenance for the success. Despite the practice of barrier such as solar powered electric fence, change in cropping pattern can be practiced where the elephant preferred crops such as paddy, maize and banana can be switched to less preferred or unpalatable crops such as ginger, turmeric, chilly, lemon, coffee, okra and so on as supported by several studies (Fernando et al. 2008; Hedges, Gunaryadi 2010; Mmbaga et al. 2017; Neupane et al. 2017). Growing such alternative cash 
crops not only help to minimize wild elephant damages but also contribute in generating cash income for the rural communities if properly managed.

But the effectiveness of solar fence will be in vain unless it is supported by additional mitigation measures or techniques; otherwise it will be branded as ineffective tool. Watch towers that was constructed along the Mechi River lacked maintenance and thus did not fit for the surveillance. Another major challenges and threats to the sustainability of the fence was that the smugglers often cut the wire and the fence was covered by the grasses and climbers in some places. A study conducted in Kenya demonstrated that electrified fences could alleviate human-elephant conflict when they were well maintained and vigorously enforced (Kioko et al. 2008). Further, they discussed that the cost of constructing, maintaining and enforcing electric fence was high and therefore the approach may only be applicable in wellresourced conservation areas.

\section{Conclusion}

Though the incident of HEC particularly crop and property damages were not completely eradicated after fence installment but there were no human attacks in the study area. In addition, the electric fence was also not in proper condition due to its poor maintenance and care. The smugglers used to break the fence and use the routes for passing through the Nepal and India border as well as the fence was covered by the grasses and climbers in some places. Thus, additional guarding mechanisms like growing unpalatable crops beside the fence should be applied for the effectiveness and sustainability of the fence.

\section{Acknowledgments}

This work was funded through Rufford Small Grants Foundation, Nepal. Official leave from work and equipment were supported by Tribhuvan University, Institute of Forestry, Pokhara, Nepal. Our team members Mr. SandipSubedi, Mr. Bishowdip Chaudhary, Mr. Rajeev Upreti and Ms. Sweta Shrestha assisted us at every steps of this study. We would like to acknowledge the suggestions and guidance of Prof. Dr. Santosh Rayamajhi, Dr. Jhamak B. Karki, Dr. Alina Evans, Dr. Thakur Silwal, Mr. Suman Bhattarai, Mr. Rajan Subedi, Mr. Yajna Prasad Timilsina and Mr. Bodhraj Subedi throughout the study period. Thanks to the DFO, Jhapa and all local people for their incredible assistance during the field works. 


\section{Literature Cited}

Acharya K. P., Paudel P. K., Neupane P. R., Köhl M. (2016): Human-wildlife conflicts in Nepal: patterns of human fatalities and injuries caused by large mammals. PLoS one. 11(9): e0161717.

Awasthi B., Singh N. B. (2015): Status of human-wildlife conflict and assessment of crop damage by wild animals in Gaurishankar conservation area, Nepal. Journal of Institute of Science and Technology. 20(1):107-111.

Davies, T. E., Wilson S., Hazarika N., Chakrabarty J., Das D., Hodgson D. J., Zimmermann A. (2011): Effectiveness of intervention methods against cropraiding elephants. Conservation Letters. 4 (5): 346-354.

District Forest Office Jhapa (2016): Annual report 2016. District Forest Office, Jhapa, Nepal.

Department of National Parks and Wildlife Conservation (2008): Department of national parks and wildlife conservation. The elephant conservation action plan of Nepal, DNPWC, Kathmandu, Nepal.

Fernando P., Kumar M.A., Williams A. C., Wikramanayake E., Aziz T., Singh S. M. (2008): Review of human-elephant conflict mitigation measures practiced in South Asia. Gland, Switzerland: WWF.

Gunaratne L. H. P., Premarathne P. K. (2005): Effectiveness of electric fencing in mitigating human-elephant conflict in Sri Lanka. EEPSEA, IDRC Regional Office for Southeast and East Asia, Singapore, SG.

Hedges S., Gunaryadi D. (2010): Reducing human-elephant conflict: do chillies help deter elephants from entering crop fields? Oryx. 44(1): 139-146.

Kioko J., Muruthi P., Omondi P., Chiyo P. I. (2008): The performance of electric fences as elephant barriers in Amboseli, Kenya. South African Journal of Wildlife Research. 38(1): 52-58.

The Kathmandu Post (2016): Solar fencing: Nepali villages relieved, but more tusker terror on Indian side. The Kathmandu Post. $4^{\text {th }}$ August, 2016. http:// kathmandupost.ekantipur.com/news/2016-08-04

Lenin, J., Sukumar R. (2008): Action plan for the mitigation of elephant-human conflict in India. Transformation. 10: 35.

Mmbaga N. E., Munishi L. K., Treydte A. C. (2017): Balancing African Elephant Conservation with Human Well-Being in Rombo Area, Tanzania. Advances in Ecology, 2017.

Ministry of Forest and Soil Conservation (2015): Community-based Action Plan 
for Human Elephant Conflict Mitigation, Jhapa: Eastern Forest Directorate Office, District Forest Office. Ministry of Forests and Soil Conservation, Nepal.

Neupane D., Johnson R. L., Risch T. S. (2014): Temporal and spatial patterns of human-elephant conflict in Nepal. In 2013 International elephant \& rhino conservation \& research symposium proceedings, USA: Pittsburgh Zoo \& PPG Aquarium (pp. 856-888).

Neupane D., Johnson R. L., Risch T. S. (2017): How do land-use practices affect human-elephant conflict in Nepal? Wildlife Biology, 2017.

Pradhan N. M. B., Williams A. C., Dhakal M. (2011): Current Status of Asian Elephants in Nepal. Gajah. 35: 87-92.

Perera B. M. A.O. (2009): The Human-Elephant Conflict: A Review of Current Status and Mitigation Methods. Gajah. 30: 41-52.

Ram A. K. (2014): Geospatial modeling to assess Asian elephant habitat suitability, migration routes and human elephant interface in eastern Nepal. M.Sc. Thesis, IOF, Pokhara, Nepal.

Shrestha R., Bajracharya S., Pradhan N. M. B. (2007): A Case Study on HumanWildlife Conflict in Nepal (With particular reference to Human-Elephant Conflict in Eastern and Western Terai Region). WWF Nepal Program, Kathmandu, Nepal.

Shrestha R., Koirala D.P. (2015): Elephant-Human Conflict in Bahundangi Region, Jhapa District, Nepal. Journal of Natural History Museum. 27: 59-65.

Yadav B. R., Dutta C., Chalise M. K., Williams C. (2015): Human-Asian wild elephant (Elephas maximus) conflicts and its socio-economic consequences in and around the protected areas of Central Terai, Nepal. BankoJanakari. 24(1): 47-54. 